\title{
Analysis of the Artistic Language in English Literary Translation
}

\author{
Li Zhu \\ Zaozhuang University, Zaozhuang Shandong, 277160, China
}

Keywords: English literature translation, Art language, Analysis

\begin{abstract}
English literary works are the same as Chinese literature works, whose article contents are rich and colorful, words are very exquisite. Thus translators must familiarize with what are the key points for English literature being translated into Chinese, at the same time, translators must master four language translation standards of English literature translation. Hence, based on the four translation standards, using the figures of speech, syntax requirements, vocabulary knowledge, phonetic method and method of combination with overall to improve the overall level of translation, it can also let the readers experience the feelings of the author more directly, hence it can let the readers have a full understanding of cultural background of that time.
\end{abstract}

\section{Introduction}

Language is the main communication method of people, language expression ability represents a person's cultural background. The culture existence will inevitably affect the language existence, Cultural level ascension also can promote the development of language and culture. According to this viewpoint, usually people think that English translation into Chinese is simple change of language, actually this kind of understanding is wrong. The language of every country in the world contains its national culture, so when translate English literature, translators need to connect with their historical background and combine with the cultural environment of the era. When do the translation, translators should integrate into the historical background of works, understand author's creation environment comprehensively, at the same time translators need to know the culture of each country at that time, so that the translators can convert the language better.

\section{Culture elements in the translation of English literature}

The language of a country represents the culture of the country.

A country's language represents the culture of the country, in order to be familiar with the application of the language of a country, translators must comprehend the country's culture background. In the development history of the world, there are representative languages in each period. Thus a good translator should understand the national cultural background of the work when do the translation of the English literature. The core element for English translated into Chinese is the cultures transfer between countries, So the English literary works translation is not only a simple change between languages, but the culture and human's ideology understanding between two different countries .

\section{A good literary works is produced in certain cultural environment.}

A famous literary work can reflect the culture of an era, as told by some scholars, literature is a mirror of the time. Some literary works recorded the most brilliant or the most miserable period of a time and widely circulated in future. When readers read a literary work, what showing in front of him/her is not just characters but more important for the reader is the culture of an era. Thus when translate English literary works, the translators should not just simply translate the work literally, and excellent translators are in the translation of the culture of this work . So when we are translating a literary work, we should not just do a rigid translation, we should consider the culture background of the work when doing translation and let the reader to be able to talk with the author of that time . 


\section{The processing principle of artistic language in English literature translation}

\section{Reasonable planning principles.}

When do the translation of English literary works, translators should have a systematic planning for the whole translation process, translate cultural elements and cultural background in English Writings into the words that can be understood by people, by doing this ,translators can let Chinese readers and English Readers have a systematic understanding of the same English Literature ,readers can get the artistic value from English works, at the same time the English translation of the article can also meet reader's reading habits .Fu Donghua, Who is the famous English translation scholars in China, when he translates the book of "Gone With The Wind", He adopts reasonable planning principles for the work firstly, He translates names of leading character in that novel as Hao Sijia, Bai Ruide etc., this kind of translation is very abundance of Chinese language and culture characteristics, thus create a very strong Chinese cultural environment . Mr. Qian Zhongshu is a famous translator in China , he is in favor of the application of reasonable planning principles, he thinks that translations with reasonable planning principles are the basis for the translation of an excellent literary works .Translation of literary works with reasonable planning principles, not only can enrich the content of the article but also be able to retain the essence of the original woks.

\section{Be faithful to the original work.}

The translation of English literary works should be faithful to the original works, Because British literature owns a very high art value and a very long historical background . Therefore, the translator should not only be faithful to the content of the literary works. but also can let the reader experience the author's emotion world from the translation. For being faithful to the original works, some people thinks that it should be in translated in accordance with the original work without one word missing, actually this kind of understanding is wrong, when doing translation for literary works, the main task of translator is to bring the original English literary works to the Chinese readers instead of simple text reporting . For translators, they should bring in their own idea and emotion during translation. They should present author's thoughts and feelings to the reader intactly, so that the time and space communication can be realized between readers and the authors, A person who has no knowledge of translation always thinks that translators master a little language knowledge and make use of English and Chinese dictionaries can be competent for this job. This thought can only be said to be a superficial understanding of the translation work. Being a qualified translator to achieve their own life value in the field of translation, he/she should completely eradicate the existence of this idea. Chinese and English dictionaries is an essential translation tool for every translator. But for Chinese and English dictionaries it is a book only after all, there is always something that can't be recorded. This is also a test of the translator, when encounter words that cannot be found on the dictionaries, translators must do the translation based on their own experience or translate according to context. Translators should also paraphrase the original works to be just perfect on the basis of fidelity to the original. If translators translate the original according to their own meaning egregiously, adding to much modifiers, even though they complete the full text translation, but this translation has been out of the author's intention, thus it will mislead the reader's understanding of the original work.

\section{Time principle.}

The country with native English is the same as China, owns a long history. Many literary works have also been produced in different historical periods, so every literary work is in connection with the historical and culture of this period, It also inherit the culture of that time. Based on this , before the translation of a foreign language literature, translators should communicate with authors carefully first or find information about the work in order to master to the specific writing background and writing environment .Take "Pride and Prejudice" as an example, translator Wang Ke get a very thorough understanding about author's life and cultural background, so he can translate different English literary works according to different social environment.For modern words in the article, Wang Ke uses a number of words to reflect the culture of the time, For example, Shang lian( do me the favor) appear in the article. The works used in the article can vividly describe figures especially their characters and psychological activities. In this way, the society of author can be completely presented to the reader, it also shows the characteristics of language arts. At present, 
almost no one is able to exceed the version of Pride and Prejudice translated by Wang Ke, it can be said that this work is unique in the history of English literature translation. No matter how beautiful words descendants used it cannot be copied again for this classic work.

\section{Processing method of art language in literary translation}

\section{Voice method.}

The main expression form of semantics is sound. For art language it is an art in itself, which is generated under the impact of sound, each subsystem of the voice system is a series of choices, configuration, arrangement that produced on the basis of it works. The translator must ensure the their translation content is in accord with original content when doing the translation for the whole work, and it should not change the original author's emotion and language environment . Based on this, an excellent translator should also skillfully use sound, rhyme, pronunciation, words with the same pronunciation but different meanings, the rhythm of the begging and the end and onomatopoeia structure arrangement .

\section{Vocabulary knowledge.}

Every country has its own language and culture, and word is the key point of carrying the language culture, it is also the most basic unit of communication between people. For translation, using words correctly occupy a dominant position in the whole translation.(1) Amplification. When translators cannot find replacement of the original words in the in the whole translation process, they need to add some necessary sentences or phrases. The added words or sentences should not change the original content, and the main purpose for adding words or sentences is to make the article more complete and let the readers read more smoothly . Sometimes it can let the author's meaning more detailed presented to the reader ; The words we added can also make the author's emotional expression more abundant, which is also a language art . (2) Deletion method. It means to delete some unnecessary words, translators should delete some repeated words according to the original content, it is in accord with the application principle of amplification, translators cannot change the original contents freely, also they can't delete a large part of the original content ,by doing that we are against the nature of translation. The main purpose to delete the words is to make the whole work more concise, and let the reader understand the author's meaning more easily. (3) Elaboration . Elaboration mainly applied in the paragraphs that do not have a clear meaning, readers will have a deviation of its content because the unclear expression, at the same time, elaboration can give the meaning of this word according to the context of the article which are not clearly expressed in the article. Therefore, translators should make a reasonable interpretation and alteration when they are doing the translation of the whole work.

\section{Comprehensive means.}

In order to translate the literary works with a very strong artistic language and let the reader feel the artistic language between the lines ,usually translators can use following methods. (1) Moving method . Changing the words order, the sentence order and the meaning of words in the translation according to different expression forms of the two languages, so as to make the whole article full of strong language arts .(2) Cutting method. Cutting method can effectively retain the meaning or cultural environment of original works. Generally speaking, translators need to comprise subordinate clause into long sentence and then make the translation, which is convenient for reader's reading.

\section{Other methods.}

In addition to the above methods, commonly used translation methods in the English literary works including grammar and rhetoric means.(1) Grammar requirements . Grammar is the rules and regulations of the whole language system, at the same time, it is also a guarantee for the standardization of the whole language. Different language will certainly have different grammar. Grammar changes in the translation are very important, it is a bridge between different languages. (2) Rhetoric means. rhetoric means mainly shown on the article with many figures of speech, this translation method mainly has following transformation forms: retention, replacement, cancellation and addition. 


\section{Conclusion}

As above, translation of English literature is very strict., therefore, it has a very high demand for translator's translation level, translators must be proficient in two different languages: original and translation. Translators must ensure to follow the original meaning of translation during their translation. Translators should do the translation according to author's creative background and make use of the smooth principle and reasonable planning principle flexibly during the whole translation process. Translators should not use these translation principles only,they should also appropriately use the language translation method including the voice, vocabulary, grammar, rhetoric and the overall combination of language translation means, which will greatly improve the efficiency of translation, so that the reader can read the authentic English literary works through reading translation works.

\section{References}

[1] Liu Cuilian. Simple discussion of application of cooperative principle in translation. Journal of Jining College, 2014,(03):233-236.

[2] Jiang Xiaoping, Josta van Rij-Hevligers. Corpus and Translation Studies: Cross culture dynamic exploration in translation. Journal of Guangzhou University (Social Science Edition), 2013,(11):1-3.

[3] Lv Wei. Discussion on the processing principle of artistic language in English literary translation. Foreign literature, 2012,(12):165-167.

[4] Sun Ji. Application analysis Nida's theory of dynamic equivalence in literary translation and the distortion and loss of cultural images in literary translation. Journal of Henan University of Urban Construction, 2014,(07):133-136. 